\title{
Psychophysiological Status and Life Quality in Individuals with Metabolic Syndrome Living in Central Kazakhstan
}

\author{
Berik Koichubekov ${ }^{1}$, Marina Sorokina ${ }^{1 *}$, llya Korshukov ${ }^{1}$, Riszhan Bakirova ${ }^{2}$, Ernur Bekov $^{2}$, Nazgul Omarbekova $^{1}$ \\ ${ }^{1}$ Department of Informatics and Biostatistics, Karaganda Medical University, Karaganda, Republic of Kazakhstan; ${ }^{2}$ Department \\ of Propaedeutic of Internal Diseases, Karaganda Medical University, Karaganda, Republic of Kazakhstan
}

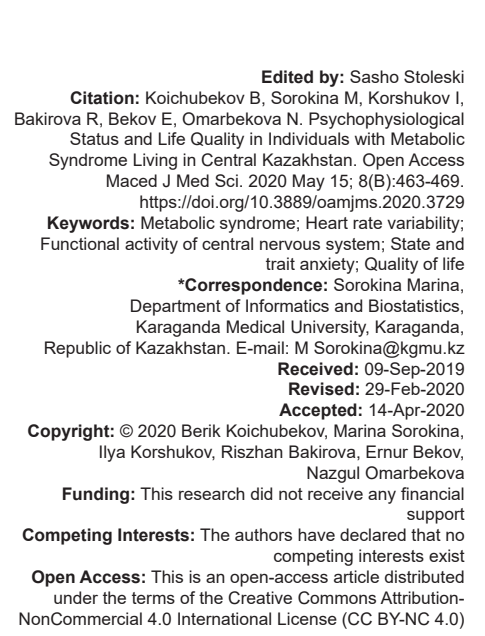

\section{Introduction}

Morbidity rate of circulatory system diseases (CSD) in Kazakhstan continues to grow and mortality rate of CSD continues to be the main cause of general population mortality among all existing disease classes [1], [2]. In industrial regions of Central Kazakhstan, the development of CSD, among which $75 \%$ are arterial hypertension, can be influenced by environmental factors [3]. The metabolic syndrome (MetS) contributes significantly to cardiovascular risk development, with abdominal obesity and hypertension being the leading components [4].

The above-mentioned justifies the necessity of researches to clarify and deepen the etiology and pathogenesis comprehension, as well as to improve diagnostics efficiency and treatment of ecologically caused health issues.

There is strong evidence that obesity leads to an increased sympathetic modulation and a decreased vagal tone, which in turn leads to the lack of autonomic control, characterized by heart rate variability (HRV) reduction. Increased muscle sympathetic nerve activity, changes in renin-angiotensin-aldosterone system and plasma catecholamines are important characteristics of obese individuals [5], [6], [7]. All these factors further contribute to increased blood pressure (BP) 8], [9], [10].

Recently, HRV has become an important instrument for autonomic modulation evaluation. In their study, Koskien et al. [11] showed that overall HRV is significantly reduced in adults with MetS. The association of individual components of MetS with HRV differed according to gender. They found that women with MetS had lower vagal activity and that there was a possible increase in sympathetic predominance.

Duanping et al. examined the relationship between cardiac autonomic activity level and MetS disorders [12]. In their research, high-frequency (HF) and low-frequency (LF) spectral powers, LF to HF ratio, and the standard deviation (SD) of all normal $\mathrm{R}-\mathrm{R}$ intervals were used as the conventional indices 
of HRV for cardiac autonomic activity measurement. The MetS disorders included hypertension, type 2 diabetes, and dyslipidemia. Findings suggest that MetS disorders adversely affect cardiac autonomic control and that reduced cardiac autonomic control may contribute to the increased risk of subsequent cardiovascular events in individuals with MetS disorders.

Stuckey et al. [7] conducted a systematic review on 14 studies published primary researches, which examined associations between HRV, MetS, and its individual risk factors. After the systematic review, it was concluded that the HRV was generally reduced in women with MetS, while results in men were inconsistent. Time and frequency domain of HRV parameters were associated with individual MetS risk factors, though gender differences exist.

It can be concluded that MetS altered autonomic nervous system (ANS) by decreasing parasympathetic activity and global HRV, at the same time, the decrease in sympathetic modulation is unclear.

According to a meta-analysis by Booth et al. [13], anxiety among the population remains and has a tendency to spread and grow. Several studies investigated associations between anxiety and MetS disorders; however, findings in this field are rather controversial. Carrol et al. [14] report on the positive relationship between generalized anxiety disorder (GAD) and MetS. Similar findings presented by Luppino et al. [15], Ribeiro et al. [16], and Kahl et al. [17] point to the association between anxiety/ depression and MetS.

In contrast, Norwegian researchers [18] found no connections between anxiety/depression and MetS. Others reported on exclusively finding depression related to MetS [19], [20].

A number of authors researched MetS influence on health-related quality of life (HRQoL); however, results were contradictory. Iranian researchers [21] showed that MetS was connected to women's low scores in physical functioning (PF), bodily pain, and social functioning domains. Dutch scientists [22] found that both obese men and women with MetS had a higher probability of poor scores in the domains of general health, vitality, social functioning, and role limitations due to emotional problems even after adjusting for body mass index (BMI). According to an earlier study by American scientists [23], this association was eliminated by controlling for BMI. Moreover, they showed that MetS was not associated with lower mental quality of life. On the contrary, Greek researchers [24] found that MetS patients showed significantly lower physical and mental components summary scores than patients without the syndrome.

The research goals were to study psychophysiological status and life quality in individuals with MetS living in Central Kazakhstan.

\section{Materials and Methods}

In Kazakhstan, the MetS is prevalent in $25 \%$ of the adult population [25]. Based on type I error ( $\alpha=5 \%)$, the required sample size $(n)$ should be equal:

$$
n=\frac{t^{2} p(100-p)}{5^{2}}=300
$$

The study was performed at Karaganda city clinical hospital. Three hundred MetS patients were examined: 192 women and 108 men, aged 18-65 years. According to the authors of diagnostics and management of MetS in the Republic of Kazakhstan, MetS diagnostics criteria should be the same as the European Standards. Studies in Kazakhstan show that the waist circumference (WC) measurement reflects mostly the degree of insulin resistance in patients [25], [26]. By the International Diabetes Federation (IDF) criteria [27] and experts of the Russian Scientific Society of Cardiology on the diagnosis and treatment of MetS [4], MetS was defined as the combination of WC $\geq 80 \mathrm{~cm}$ in women and $\geq 94 \mathrm{~cm}$ in men with two and more risk factors (triglycerides $\geq 1.7$ $\mathrm{mmol} / \mathrm{l}$, high-density lipoprotein (HDL) cholesterol $<1.2$ in women, $\mathrm{HDL}$ cholesterol $<1.0 \mathrm{mmol} / \mathrm{l}$ in men, fasting plasma glucose $\geq 5.6 \mathrm{mmol} / \mathrm{l}$, BP $\geq 130 / 85 \mathrm{~mm} \mathrm{Hg}$ or taking antihypertensive medication). Patients with hyperglycemia had prediabetes and their blood glucose is higher than usual but not so high as to constitute diabetes. Cardiac arrhythmia and cognitive disorder were excluding criteria.

Ethics Committee approved the study. The patients gave informed consent to participate in the research.

\section{Data collection}

WC, triglycerides, HDL cholesterol, fasting plasma glucose, and BP measurements were observed. Arterial hypertension $(\mathrm{AH})$ diagnostics were done according to the clinical recommendations [28] and the clinical protocol on $\mathrm{AH}$ of Healthcare and Social Development of the Republic of Kazakhstan [29].

Assessment of autonomic regulation of the heart was performed by analyzing HRV using statistical methods and spectral analysis [30].

Central nervous system (CNS) activation level was assessed by simple visual-motor reaction (SVMR) [31].

To determine patients' anxiety level, the Spielberger State-Trait Anxiety Inventory was employed [32].

The patients' psychophysiological state was evaluated by the Lüscher color test [33].

SF-36 questionnaire was used for HRQoL assessment [34]. 


\section{Statistical analysis}

Quantitative data, in the case of the normal distribution, were presented as mean values (M) and standard errors of the mean $(\mathrm{m})$. In the case of non-normal distribution, data were presented in the form of median $(\mathrm{Me})$, lower $\left(\mathrm{Q}_{25}\right)$, and upper $\left(\mathrm{Q}_{75}\right)$ quartiles. Qualitative data were presented in the form of a percentage of $(p)$ with a $95 \%$ confidence interval (Cl). Relationships were assessed by Spearman's rank correlation coefficient. $\mathrm{R}$ software was used for calculations.

\section{Results}

The clinical study involved 300 patients with MetS, mean age $52.29 \pm 8.76$ years. Females predominated among the examined patients $(63.93 \pm 6.15 \%)$. Age and gender are presented in Table 1.

Metabolic disorders were most frequent among 40-49 and 50-59 age groups for total subjects $(26.33 \%$; $\mathrm{Cl}[21.44-31,70] \%$ and $41.00 \%$; $\mathrm{Cl}[35.38-46.80] \%$, respectively).

The main components of MetS were obesity (211 patients [70.33\%; Cl $\{64.81-75.45\} \%])$ and hypertension (250 patients [83.33\% $\mathrm{Cl}\{78.62-87.37\} \%]$ ) with predominating Grade 1 hypertension: (140-159) $\mathrm{mmHg}$ systolic and/or (90-99) $\mathrm{mmHg}$ diastolic BP (66.67\%; Cl [61.02-71.98]\%). Dyslipidemia was diagnosed in $46 \%$ of cases $(\mathrm{Cl}$ [40.26-51.82]\%) and dysglycemia in $27 \%$ (Cl [22.99-33.45]\%).

When describing the condition of MetS patients, it is necessary to evaluate not only carbohydrate and lipid metabolism indicators but also neurohumoral system parameters. To assess the neurohumoral system, HRV analysis was used. This analysis provides information about heart rhythm autonomic regulation and overall status of the ANS [35], [36].
Table 2 data are the integral indicators of HRV in general, reflecting a balance between sympathetic and parasympathetic nervous systems influences.

Presented HRV statistical indicators are generally significantly lower than normative figures. In the study group, SDNN, RMSSD, pNN50\% decreased 2,3 , and 4 times, respectively. The average pulse rate was around 80 beats $/ \mathrm{min}$. Aforementioned indicators give evidence for autonomic balance shift toward sympathetic nervous system predominance and significant strain in the heart rhythm regulation system.

Spectral analysis components (Table 3) characterize HRV periodic components and can be used for a separate description of both branches of the ANS.

There is a significant decrease in total power (TP) of the cardiointervalogram's spectrum and individual spectral components in the study group, which is evidence of the significant rhythm stabilization. HF component of the spectrum is weakly expressed both in absolute terms HF $=(301.83 \pm$ 98.55) $\mathrm{ms}^{2}$ and percentage $\mathrm{HF}=(17.56 \pm 3.31) \%$ to TP. These fluctuations reflect vagal influences on cardiac rhythm and point to the decreasing activity of the parasympathetic branch in the study group. Low frequency $(L F)=(899.19 \pm 398.14) \mathrm{ms}^{2}$ for the study group, $(1170 \pm 416) \mathrm{ms}^{2}$ for healthy individuals, and very low-frequency components VLF $=(330.68 \pm$ 107.68) $\mathrm{ms}^{2}$ against the normal $(1267 \pm 400) \mathrm{ms}^{2}$ are weakly expressed. Therefore, sympathetic branch activity is also significantly lower in comparison to healthy individuals. Nevertheless, there is a balance shift toward sympathetic branch since LF/HF $=3.77 \pm 0.92$.

Thus, no significant peaks were observed, while evaluating the percentage contribution of each spectral component to the total spectral power. $\mathrm{LF}=36.12 \%$ waves prevail slightly.

The studied sample contained the least number of patients with low trait anxiety (11.11\%) (Table 4).

The number of patients with moderate trait anxiety level was two times greater $-27.78 \%$. More than half of the patients $(61.11 \%)$ had a high level of trait anxiety.

Table 1: Distribution of patients by age and gender

\begin{tabular}{|c|c|c|c|c|c|c|c|c|c|}
\hline \multirow{2}{*}{$\begin{array}{l}\text { Age group } \\
\text { years }\end{array}$} & \multicolumn{3}{|c|}{ Total } & \multicolumn{3}{|c|}{ Male } & \multicolumn{3}{|c|}{ Female } \\
\hline & $\mathrm{n}$ & $\%$ & $95 \% \mathrm{Cl}$ & $\mathrm{n}$ & $\%$ & $95 \% \mathrm{Cl}$ & $\mathrm{n}$ & $\%$ & $95 \% \mathrm{Cl}$ \\
\hline $20-29$ & 15 & 5.00 & $2.83-8.11$ & 5 & 4.63 & $1.52-10.47$ & 10 & 5.21 & $2.53-9.37$ \\
\hline 30-39 & 49 & 16.33 & $12.33-21.01$ & 15 & 13.89 & $7.99-21.87$ & 34 & 17.71 & $12.59-23.86$ \\
\hline $40-49$ & 79 & 26.33 & $21.44-31.70$ & 39 & 36.11 & $27.09-45.92$ & 40 & 20.83 & $15.32-27.27$ \\
\hline $50-59$ & 123 & 41.00 & $35.38-46.80$ & 29 & 26.85 & $18.78-36.24$ & 94 & 48.96 & $41.69-56.26$ \\
\hline $60-65$ & 34 & 11.33 & $7.98-15.48$ & 20 & 18.52 & $11.69-27.14$ & 14 & 7.29 & $4.04-11.93$ \\
\hline Total & 300 & 100 & & 108 & & & 192 & & \\
\hline
\end{tabular}

Table 2: Statistical HRV indicators ( $M \pm m$ )

\begin{tabular}{lll}
\hline Indicator & Study group & Normal \\
\hline HR beats/min & $79.31 \pm 3.27$ & $60-80$ \\
RRNN (ms) & $774.14 \pm 30.75$ & $800 \pm 56$ \\
SDNN (ms) & $29.74 \pm 4.67$ & $63 \pm 35$ \\
RMSSD (ms) & $20.42 \pm 3.46$ & $64 \pm 6$ \\
pNN50\% & $5.09 \pm 2.39$ & $21.1 \pm 5.1$ \\
\hline HR beats/min is the heart rate, RRNN (ms) is the mean duration of all normal R-R intervals, RMSSD (ms) is \\
the root mean square of the successive differences of all R-R intervals, SDNN (ms) is the standard deviation \\
of R-R intervals, pNN50\% is the number of adjacent intervals differing more than 50 ms expressed as a \\
percentage of all the intervals in the collecting period.
\end{tabular}

Table 3: Spectral HRV indicators $(M \pm m)$

\begin{tabular}{lll}
\hline Indicator & Study group & Normal \\
\hline TP $\left(\mathrm{ms}^{2}\right)$ & $1855.06 \pm 647.4$ & $3105 \pm 1018$ \\
$\mathrm{HF}\left(\mathrm{ms}^{2}\right)$ & $301.83 \pm 98.55$ & $668 \pm 203$ \\
$\mathrm{LF}\left(\mathrm{ms}^{2}\right)$ & $899.19 \pm 398.14$ & $1170 \pm 416$ \\
VLF $\left(\mathrm{ms}^{2}\right)$ & $330.68 \pm 107.68$ & $1267 \pm 400$ \\
HF\% & $17.56 \pm 3.31$ & $15-45$ \\
LF\% & $36.12 \pm 4.34$ & $20-50$ \\
VLF\% & $21.82 \pm 2.57$ & $20-50$ \\
LF/HF & $3.77 \pm 0.92$ & $1.5-2.0$ \\
\hline TP is the total power, HF is the high frequency, LF is the low frequency, VLF is the very low frequency. They are \\
determined when heart rate variability is plotted as a frequency at which the length of the R-R intervals changes.
\end{tabular}


The greatest number of patients $(85.71 \%)$ was characterized by a low level of state anxiety, lack of tension, and nervousness at the time of the study. Only $7.14 \%$ of patients with high-level state anxiety were identified during the psychophysiological examination.

The study of preferred colors' positional frequency distribution in MetS patients (Table 5) showed the presence of color selecting specialties in the group.

In $37.5 \%$ of cases, red color did not occupy the first three positions, i.e., was rejected. There was a shift of yellow color to the eighth position of the color selection. More than half of the patients $(56.3 \%)$ chose a green color for the first and second positions. Brown color appears on the second position in $31.25 \%$ of cases.

About $80 \%$ of the examined patients were characterized by a low level of CNS activation (Table 6).

Time reaction $\mathrm{Me}$ in this group was 321 msec $\left(Q_{25}=313 \mathrm{msec} ; Q_{75}=337 \mathrm{msec}\right)$. The standard deviation Me of the time reaction was $99 \mathrm{msec}\left(Q_{25}=80\right.$ msec; $Q_{75}=113 \mathrm{msec}$ ). Increases of the time reaction to visual triggers above $270 \mathrm{msec}$ and its standard deviation values above $80 \mathrm{msec}$ show inhibitory processes prevalence and reduced level of CNS functionality.

The remaining part of the patients $(20 \%)$ showed average level of CNS activation and stable condition of regulatory mechanisms. Time reaction $\mathrm{Me}$ in this group was $287 \mathrm{msec}\left(Q_{25}=278 \mathrm{msec} ; Q_{75}=290\right.$ $\mathrm{msec}$ ). Time reaction standard deviation was $66 \mathrm{msec}$ $\left(Q_{25}=56 \mathrm{msec} ; Q_{75}=67 \mathrm{msec}\right)$. No patients in the studied sample had a high level of CNS activation. Half of the examined patients showed moderate resistance of visual-motor reaction.

Table 4: Anxiety levels frequency distribution among MetS patients

\begin{tabular}{lllll}
\hline Indicator & & $\boldsymbol{n}$ & $\%$ & $95 \% \mathrm{Cl}$ \\
\hline Level of trait anxiety & No or low & 8 & 11.11 & $5.07-21.25$ \\
& Moderate & 19 & 27.78 & $16.73-37.56$ \\
& High & 43 & 61.11 & $49.03-72.83$ \\
Level of state anxiety & No or low & 60 & 85.71 & $75.29-92.93$ \\
& Moderate & 5 & 7.14 & $2.36-15.89$ \\
& High & 5 & 7.14 & $2.36-15.89$ \\
\hline No or low anxiety level: STAl scores (20-37), moderate anxiety level: STAl scores (38-44), high anxiety \\
level: STAl scores (45-80).
\end{tabular}

The statistical significant correlations between functional level of CNS activation and level of trait anxiety $\left(r_{s}=-0.516, p=0.002\right)$, and position of the yellow color $\left(r_{s}=0.581, p=0.015\right)$ were identified in the study sample.

Table 5: Preferred colors' positional frequency distribution in MetS patients

\begin{tabular}{lllllllll}
\hline Color & Position & & & & & \\
& 1-st (\%) & 2-nd (\%) & 3-rd (\%) & 4-th (\%) & 5-th (\%) & 6-th (\%) & 7-th (\%) & 8-th (\%) \\
\hline 1. Blue & 6.25 & 6.25 & 6.25 & 18.75 & 50.00 & 12.50 & 0.00 & 0.00 \\
2. Green & 31.25 & 25.00 & 31.25 & 12.50 & 0.00 & 0.00 & 0.00 & 0.00 \\
3. Red & 31.25 & 18.75 & 12.50 & 6.25 & 6.25 & 12.50 & 6.25 & 6.25 \\
4. Yellow & 18.75 & 0.00 & 25.00 & 25.00 & 0.00 & 12.50 & 0.00 & 18.75 \\
5. Violet & 12.50 & 18.75 & 6.25 & 12.50 & 6.25 & 31.25 & 12.50 & 0.00 \\
6. Brown & 0.00 & 31.25 & 0.00 & 0.00 & 0.00 & 25.00 & 37.50 & 6.25 \\
7. Black & 0.00 & 0.00 & 6.25 & 6.25 & 12.50 & 0.00 & 18.75 & 56.25 \\
0. Gray & 0.00 & 0.00 & 12.50 & 18.75 & 25.00 & 6.25 & 25.00 & 12.50 \\
\hline
\end{tabular}

$\mathrm{PF}$ in the study group was at a high level, Me of PF was 80 points, according to Table 7. Patients' physical condition did not prevent role-PF (RP) achievement - Me of RP was equal to 100 points.

Life quality is significantly affected by pain. According to the questionnaire, half of the patients had $<60$ points on BP scale, while interquartile range $(\Delta Q)$ was from 41 to 100 points. This corresponds to patients' low $\mathrm{GH}$ level assessment. Me of $\mathrm{GH}$ was 52 points and $\Delta Q$ was from 45 to 62 points.

During mental health evaluation, it was found that the patients had a high level of fatigue and low vitality. Me of values on VT scale was 60 points.

Psychological health was average overall. Me of small dispersion $\mathrm{MH}$ scale was 68 points $(\Delta \mathrm{Q}$ was from 52 to 80 points). At the same time, emotional condition was satisfactory and did not have a significant impact on the quality of daily activity, Me of RE was 100 points. High social activity (communication, spending time with friends, family, neighbors, and team) was observed to be preserved in the patients, which is traditional for Kazakhstan mentality (Me of SF was 87 points).

\section{Discussion}

Metabolic disorders were most frequent among 40-49 and 50-59 age groups. The main components of MetS were obesity and hypertension with predominating Grade 1 hypertension.

Table 6: Indicators of simple visual-motor reaction

\begin{tabular}{lllll}
\hline Indicator & & $\mathrm{n}$ & $\%$ & $95 \% \mathrm{Cl}$ \\
\hline Functional level of CNS activation & low & 56 & 80.00 & $68.73-88.61$ \\
& moderate & 14 & 20.00 & $11.39-31.27$ \\
Reaction resistance & high & - & - & - \\
& low & 13 & 18.57 & $10.28-29.66$ \\
& moderate & 35 & 50.00 & $37.80-62.20$ \\
& high & 22 & 31.43 & $20.85-43.63$ \\
\hline
\end{tabular}

Heart rate is intricately regulated by complex interactions of multiple mechanisms, including sympathetic and parasympathetic nervous system, as well as hormonal homeostasis. HRV, which means variation of beat-to-beat interval, is a noninvasive way to evaluate cardiac ANS functions [37]. Given the potential mechanism underlying the development of MetS and its major cardiovascular complications, HRV is well recognized for its predictive power.

Table 7: Life quality domains in MetS patients according to SF-36 questionnaire

\begin{tabular}{lllll}
\hline Domains & & $\mathrm{Me}$ & $\mathrm{Q}_{25}$ & $\mathrm{Q}_{75}$ \\
\hline Physical health & Physical functioning & 80.0 & 60.00 & 95.0 \\
& Role-physical functioning & 100.0 & 75.00 & 100.0 \\
& Bodily pain & 62.0 & 41.00 & 100.0 \\
& General health & 52.0 & 45.00 & 62.0 \\
Mental health & Vitality & 60.0 & 47.50 & 75.0 \\
& Role-emotional & 100.0 & 66.00 & 100.0 \\
& Mental health & 68.0 & 52.00 & 80.0 \\
& Social functioning & 87.0 & 62.00 & 100.0 \\
\hline
\end{tabular}


In the present study, several conventional parameters (SDNN, RMSSD, pNN50\%) were able to distinguish MetS.

The clustering of various cardiovascular risks referred to as the MetS have led to the fact that patients with cardiovascular diseases often have one or more MetS components or undetected diabetes mellitus [38]. Cardiac dynamic alterations are associated with increased cardiovascular risk profile such as insulinresistance, endothelial dysfunction, arterial stiffening, cardiac hypertrophy, and sympathetic activation [39]. Results from previous studies have shown that MetS factors by themselves, or in any combination, portend cardiovascular disease, and many other adverse outcomes [40].

Stuckey et al. [7] reviewed 14 investigations evaluating the relationship between HRV and MetS and found that high fasting plasma glucose (FPG) might be associated with decreased LF and HF, increased LF/HF ratio, along with neural effects on TP and VLF. The impact of FPG could be roughly interpreted as decreasing the parasympathetic tone and the mixture of both sympathetic and parasympathetic tone but not yet reaching the decrease of total autonomic tone. However, the results were not totally the same with our findings in which both sympathetic and parasympathetic tone, as well as total autonomic nervous tone, were decreased in MetS patients by means of significantly decreased values of VLF, LF, HF, and TP. It is possible that the humoral-metabolic component acquires all the more increasing role in heart rhythm regulation. The identified set of HRV indicators allows diagnosing neurocardiopathy due to systemic and local neurohormonal disorders.

It is a known fact that high trait anxiety correlates directly with neurotic conflict, emotional and neurotic breakdown, and psychosomatic diseases [41]. Moreover, at the high level of trait anxiety, clinical course of cardiovascular disease runs worse than at the average and low levels [42].

Several prior studies of MetS have documented that anxiety had a significant positive association with MetS [43], [44]. This study showed that high trait anxiety level but not state anxiety level accompanied MetS, as already reported earlier by Lemche et al. [45]. More than half of the patients had a high level of trait anxiety. Trait anxiety describes a stable tendency to perceive a large range of situations as a threat and to react with a state of anxiety. However, initially, anxiety is not a negative trait. A certain level of anxiety is a natural and necessary feature of active personality. In addition, trait anxiety characterizes vulnerability (or resilience) to influence of various stressors in general. Anxiety as a state (state anxiety) includes components such as subjective feelings of tension, anxiety, agitation, fear, and ANS activation. State anxiety is characterized by stress level at the time of the study. State anxiety of the same individual can vary at different times [46]. The greatest number of patients was characterized by a low level of state anxiety, lack of tension, and nervousness at the time of the study. However, a small number of patients with high-level state anxiety were revealed in this study. These patients were in a state characterized by subjective emotions, stress, anxiety, concern, and nervousness. It is possible that this state appeared as an emotional response to the situation caused by the medical check-up.

According to M. Lüscher's data, color choices "34215607" or "43251607" are close to average standard values and reflect an optimistic and cheerful personality position, absence of tension, anxiety, and stress [47]. The first position of the color selection corresponds to lead personal tendencies and predominant aspects of the motivational sphere. More than half of the patients chose a green color for the first and second positions. It follows from these color choices that rigidly introvert tendencies with the need to defend their own position, defensiveness, and aggressiveness of defensive nature were more common in the study group. Red color shift exposes emotional-vegetative tension, to the point of physiological and nervous exhaustion in the study sample. The choice of the yellow color as the last indicates anxiety and depression in addition to that. The choice of brown color, as the preferred color, characterizes the high level of anxiety and points to the need of anxiety reduction and the pursuit of psychological and physical comfort. In addition, brown on the second position reflects an anxiety problem, which has a vital (somatic) overtone and is associated with malaise, fatigue, and overexertion.

Examination of SVMR allowed revealing patients with persistent predominance of inhibition processes and a reduced level of CNS functional possibilities. Simultaneously the higher the level of trait anxiety and depression, the less functional level of CNS activation was in MetS patients.

MetS patients are active both in physical and social spheres. Their aspirations were explicitly expressed as communication, interaction with others, and social functions fulfillment. Bodily pain syndrome greatly influences MetS patients' life quality. The patients evaluate their health level as being low. A significant number of patients have noted a decline of vital energy. Emotional state of the patients did not affect the quality of their daily activities.

\section{References}

1. Roth GA, Johnson C, Abajobir A, Abd-Allah F, Abera SF, Abyu G, et al. Global, regional, and national burden of cardiovascular diseases for 10 causes, 1990 to 2015. J Am Coll Cardiol. 2017;70(1):1-25.

PMid:28527533 
2. Marchenko AB, Nildibayeva FU, Sorokina MA, Laryushina EM, Turgunova LG, Turmukhambetova AA. Level of FABP3, FABP4, $\mathrm{Nt}$-proBNP and total cardiovascular risk in the population of Central Kazakhstan. Open Access Maced J Med Sci. 2017;5(1):33-6. https://doi.org/10.3889/oamjms.2017.021 PMid:28293313

3. Ibraeva LK, Azhimetova GN, Amanbekova AU, Bakirova RE. Cardiovascular diseases in the population of industrial towns and environmental factors. Ter Arkh. 2015;87(1):76-8. https:// doi.org/10.17116/terarkh201587176-78

PMid:25823273

4. Scott CL. Diagnosis, prevention, and intervention for the metabolic syndrome. Am J Cardiol. 2003;92(1A):35I-42I.

PMid: 12867253

5. Grassi G, Seravalle G, Colombo M, Bolla G, Cattaneo BM, Cavagnini $F$, et al. Body weight reduction, sympathetic nerve traffic, and arterial baroreflex in obese normotensive humans. Circulation. 1998;97(20):2037-42. https://doi.org/10.1161/01. cir.97.20.2037

PMid:9610534

6. Abreu LC. Heart rate variability as a functional marker of development. J Hum Growth Dev. 2012;22(3):279-81.

7. Stuckey MI, Tulppo MP, Kiviniemi AM, Petrella RJ. Heart rate variability and the metabolic syndrome: a systematic review of the literature. Diabetes Metab Res Rev. 2014;30(8):784-93. https://doi.org/10.1002/dmrr.2555

PMid:24816921

8. Carnethon MR, Prineas RJ, Temprosa M, Zhang ZM, Uwaifo G, Molitch ME, et al. The association among autonomic nervous system function, incident diabetes, and intervention arm in the diabetes prevention program. Diabetes Care. 2006;29(4):914-9. https://doi.org/10.2337/diacare.29.04.06.dc05-1729

PMid: 16567837

9. La Rovere MT, Bigger JT, Marcus FI, Mortara A, Schwartz PJ, Investigators $\mathrm{A}$. Baroreflex sensitivity and heart-rate variability in prediction of total cardiac mortality after myocardial infarction. Lancet. 1998;351(9101):478-84. https://doi.org/10.1016/ s0140-6736(97)11144-8

PMid:9482439

10. Kleiger RE, Miller JP, Bigger JT, Moss AJ. Decreased heart-ratevariability and its association with increased mortality after acute myocardial-infarction. Am J Cardiol. 1987;59(4):256-62. https:// doi.org/10.1016/0002-9149(87)90795-8

PMid:3812275

11. KoskinenT,KahonenM, JulaA, MattssonN, LaitinenT, Keltikangasjarvinen L, et al. Metabolic syndrome and short-term heart rate variability in young adults. Diabetic Med. 2009;26(4):354-61. https://doi.org/10.1111/j.1464-5491.2009.02686.x

PMid:19388964

12. Liao DP, Sloan RP, Cascio WE, Folsom AR, Liese AD, Evans GW, et al. Multiple metabolic syndrome is associated with lower heart rate variability the atherosclerosis risk in communities study. Diabetes Care. 1998;21(12):2116-22. https://doi.org/10.2337/ diacare.21.12.2116

PMid:9839103

13. Booth RW, Sharma D, Leader TI. The age of anxiety? It depends where you look: Changes in STAI trait anxiety, 1970-2010. Soc Psychiatry Psychiatr Epidemiol. 2016;51(2):193-202. https://doi. org/10.1007/s00127-015-1096-0

PMid:26190152

14. Carroll D, Phillips AC, Thomas GN, Gale CR, Deary I, Batty GD. Generalized anxiety disorder is associated with metabolic syndrome in the Vietnam experience study. Biol Psychiatry. 2009;66(1):91-3. https://doi.org/10.1016/j. biopsych.2009.02.020

\section{PMid:19344891}

15. Luppino FS, Dortland AK, Wardenaar KJ, Bouvy PF, Giltay EJ, Zitman FG, et al. Symptom dimensions of depression and anxiety and the metabolic syndrome. Psychosom Med. 2011;73(3):25764. https://doi.org/10.1097/psy.0b013e31820a59c0 PMid:21257975

16. Ribeiro RP, Marziale MH, Martins JT, Ribeiro PH, do Carmo Cruz Robazzi ML, Dalmas JC. Prevalence of metabolic syndrome among nursing personnel and its association with occupational stress, anxiety and depression. Rev Lat Am Enfermagem. 2015;23(3):435-40. https://doi. org/10.1590/0104-1169.0383.2573 PMid:26155007

17. Kahl KG, Schweiger U, Correll C, Mueller C, Busch ML, Bauer M, et al. Depression, anxiety disorders, and metabolic syndrome in a population at risk for Type 2 diabetes mellitus. Brain Behav. 2015;5(3):e00306. https://doi.org/10.1002/brb3.306 PMid:25642391

18. HildrumB,MykletunA, MidthjellK, IsmailK,DahIAA. Noassociation of depression and anxiety with the metabolic syndrome: the Norwegian HUNT study. Acta Psychiatr Scand. 2009;120(1):1422. https://doi.org/10.1111/j.1600-0447.2008.01315.x PMid: 19120047

19. Skilton MR, Moulin P, Terra JL, Bonnet F. Associations between anxiety, depression, and the metabolic syndrome. Biol Psychiatry. 2007;62(11):1251-7. https://doi.org/10.1016/j. biopsych.2007.01.012

PMid:17553465

20. Takeuchi T, Nakao M, Nomura K, Yano E. Association of metabolic syndrome with depression and anxiety in Japanese men. Diabetes Metab. 2009;35(1):32-6. https://doi.org/10.1016/j. diabet.2008.06.006

PMid: 19046916

21. Amiri P, Hosseinpanah F, Rambod M, Montazeri A, Azizi F. Metabolic syndrome predicts poor health-related quality of life in women but not in men: Tehran lipid and glucose study. J Womens Health. 2010;19(6):1201-7. https://doi.org/10.1089/ jwh.2009.1710

PMid:20482255

22. Slagter SN, van der Klauw MM, van Vliet-Ostaptchouk J Keers JC, Lutgers HL, van Beek AP, et al. Health-related quality of life and the relation to metabolic syndrome, Type 2 diabetes, degree of obesity and low-grade inflammation in obese individuals. Diabetologia. 2014;57:S424-S. https://doi. org/10.1371/journal.pone.0140599

23. Tsai AG, Wadden TA, Sarwer DB, Berkowitz RI, Womble LG, Hesson LA, et al. Metabolic syndrome and health-related quality of life in obese individuals seeking weight reduction. Obesity. 2008;16(1):59-63. https://doi.org/10.1038/oby.2007.8 PMid: 18223613

24. Tziallas D, Kastanioti C, Kostapanos MS, Skapinakis P, Elisaf MS, Mavreas V. The impact of the metabolic syndrome on health-related quality of life: A cross-sectional study in Greece. Eur J Cardiovasc Nurs. 2012;11(3):297-303. https://doi. org/10.1016/j.ejcnurse.2011.02.004 PMid:21398183

25. Oshakbayev K, Dukenbayeva B, Togizbayeva G, Durmanova A, Gazaliyeva M, Sabir A, et al. Weight loss technology for people with treated Type 2 diabetes: A randomized controlled trial. Nutr Metab. 2017; 14:11. https://doi.org/10.1186/s12986-017-0163-9 PMid:28163748

26. Sadykova A, Shalkharova ZS, Shalkharova ZN, Sadykova K, Madenbay K, Zhunissova M, et al. Metabolic syndrome and its components in Southern Kazakhstan: A cross-sectional study. Int Health. 2018;10(4):268-76. https://doi.org/10.1093/inthealth/ 
ihy027

PMid:29718371

27. Alberti K, Zimmet $P$, Shaw J. The metabolic syndrome a new worldwide definition. Lancet. 2005;366(9491):1059-62. https:// doi.org/10.1016/s0140-6736(05)67402-8

PMid:16182882

28. Williams B, Mancia G, Spiering W, Rosei EA, Azizi M, Burnier M, et al. 2018 Practice guidelines for the management of arterial hypertension of the European society of hypertension $(\mathrm{ESH})$ and the European society of cardiology (ESC). Blood Pressure. 2018;27(6):314-40. https://doi.org/10.1097/ hjh.0000000000001961 PMid:30380928

29. Republican Center for Health Development of Healthcare and Social Development Ministry of Kazakhstan: E-database of Clinical Protocols Available from: http://www.rcrz.kz/index.php/ en. [Last accessed on 2020 Mar 03].

30. CammAJ, Malik M, Bigger JT, Breithardt G, Cerutti S, Cohen RJ, et al. Heart rate variability. Standards of measurement, physiological interpretation, and clinical use. Eur Heart J. 1996;17(3):354-81. https://doi.org/10.1093/oxfordjournals.eurhearti.a014868 PMid:8598068

31. Woods DL, Wyma JM, Yund EW, Herron TJ, Reed B. Factors influencing the latency of simple reaction time. Front Hum Neurosci. 2015;9:131. https://doi.org/10.3389/ fnhum.2015.00131

PMid:25859198

32. Spielberger CD, Gorsuch RL, Lushene R, Vagg PR, Jacobs GA. Manual for the State-Trait Anxiety Inventory. Palo Alto, CA: Consulting Psychologists Press; 1983.

33. Lüscher M. In: Scott IA, editor. The Lüscher Color Test. New York: Washington Square Press; 1969.

34. McHorney CA, Ware JE, Raczek AE. The mos 36-item shortform health survey (sf-36) 2. Psychometric and clinicaltests of validity in measuring physical and mental-health constructs. Med Care. 1993;31(3):247-63. https://doi. org/10.1097/00005650-199303000-00006

PMid:8450681

35. Berntson GG, Bigger JT, Eckberg DL, Grossman P, Kaufmann PG, Malik M, et al. Heart rate variability: Origins, methods, and interpretive caveats. Psychophysiology. 1997;34(6):623-48. https://doi.org/10.1111/j.1469-8986.1997. tb02140.x

\section{PMid:9401419}

36. Gress TW, Nieto FJ, Shahar E, Wofford MR, Brancati FL. Hypertension and antihypertensive therapy as risk factors for Type 2 diabetes mellitus. N Engl J Med. 2000;342(13):905-12. https://doi.org/10.1056/nejm200003303421301 PMid:10738048

37. Thayer JF, Yamamoto SS, Brosschot JF. The relationship of autonomic imbalance, heart rate variability and cardiovascular disease risk factors. Int J Cardiol. 2010;141(2):122-31. https:// doi.org/10.1016/j.ijcard.2009.09.543

PMid:19910061

38. Ryden L, Grant PJ, Anker SD, Berne C, Cosentino F, Danchin N, et al. ESC Guidelines on diabetes, pre-diabetes, and cardiovascular diseases developed in collaboration with the EASD. Eur Heart J. 2013;34(39):3035. https://doi.org/10.1093/ eurheartj/eht108

PMid:23996285

39. Grassi G, Arenare F, Quarti-Trevano F, Seravalle G, Mancia G. Heart rate, sympathetic cardiovascular influences, and the metabolic syndrome. Prog Cardiovasc Dis. 2009;52(1):31-7. https://doi.org/10.1016/j.pcad.2009.05.007

PMid:19615491

40. Kahn R. Metabolic syndrome what is the clinical usefulness? Lancet. 2008;371(9628):1892-3. https://doi.org/10.1016/ s0140-6736(08)60731-x

PMid: 18501420

41. Spielberger CD, Reheiser EC. Assessment of emotions: Anxiety, anger, depression, and curiosity. Appl Psychol Health Well Being. 2009;1(3):271-302. https://doi. org/10.1111/j.1758-0854.2009.01017.x

42. Celano CM, Daunis DJ, Lokko HN, Campbell KA, Huffman JC Anxiety disorders and cardiovascular disease. Curr Psychiatry Rep. 2016;18(11):101. https://doi.org/10.1007/ s11920-016-0739-5 PMid:27671918

43. Tang F, Wang G, Lian Y. Association between anxiety and metabolic syndrome: A systematic review and meta-analysis of epidemiological studies. Psychoneuroendocrinology. 2017;77:112-21. https://doi.org/10.1016/j.psyneuen.2016.11.025 PMid:28027497

44. Akbari H, Sarrafzadegan N, Aria H, Garaei AG, Zakeri H. Anxiety but not depression is associated with metabolic syndrome: The Isfahan healthy heart program. J Res Med Sci. 2017:22:90. https://doi.org/10.4103/jrms.jrms_288_16 PMid:28919917

45. Lemche AV, Chaban OS, Lemche E. Trait anxiety but not state anxiety level associates with biomarkers for hypertension in the metabolic syndrome. Psychophysiology. 2016;53(6):914-20. https://doi.org/10.1111/psyp.12623

PMid:26841205

46. Endler NS, Kocovski NL. State and trait anxiety revisited. J Anxiety Disord. 2001;15(3):231-45. https://doi.org/10.1016/ s0887-6185(01)00060-3

PMid: 11442141

47. Corotto LV, Hafner JL. The luscher color test relationship between color preferences and behavior. Perceptual Motor Skills. 1980;50(3):1066. https://doi.org/10.2466/pms.1980.50.3c.1066 PMid:7413380 